\title{
A narrative review on the management of medication overuse headache: the steep road from experience to evidence
}

\author{
Paolo Rossi · Rigmor Jensen · Giuseppe Nappi · \\ Marta Allena $\cdot$ The COMOESTAS Consortium
}

Received: 9 July 2009/Accepted: 9 September 2009/Published online: 3 October 2009

(C) Springer-Verlag 2009

\begin{abstract}
The management of medication overuse headache $(\mathrm{MOH})$ is based essentially on the withdrawal of the overused drug(s). Drug withdrawal is performed according to widely differing protocols, both within and across countries; therefore, therapeutic recommendations for the acute phase of detoxification vary considerably among studies. Basically, the aims of $\mathrm{MOH}$ management are: (a) to withdraw the overused $\operatorname{drug}(\mathrm{s})$; (b) to alleviate withdrawal symptoms by means of a bridge therapy, which includes pharmacological and non-pharmacological support, designed to help the patient to tolerate the withdrawal process; (c) to prevent relapse. Today, there is extensive debate over the best strategies for achieving these goals and the different aspects of this debate are discussed in this review.
\end{abstract}

The members of the Comoestas Consortium are given in the Appendix

P. Rossi · G. Nappi · M. Allena ( $\square)$

IRCCS "Neurological Institute C. Mondino" Foundation,

University Centre for Headache and Adaptive Disorders

(UCADH), Pavia Section, Pavia, Italy

e-mail: Marta.allena@mondino.it

P. Rossi

Headache Clinic INI Grottaferrata, Rome, Italy

R. Jensen

Danish Headache Centre, Department of Neurology,

Glostrup Hospital, University of Copenhagen,

Glostrup, Denmark

G. Nappi · M. Allena

Chair of Neurology, University "La Sapienza", Rome, Italy

P. Rossi $(\bowtie)$

Headache Clinic, INI Grottaferrata,

Via Suvereto 250, 00139 Rome, Italy

e-mail: paolo.rossi90@alice.it
The authors searched for the best available evidence relating to the following questions: should medication withdrawal be abrupt or gradual? Should patients receive replacement therapy? What are the most effective therapeutic programmes for controlling withdrawal symptoms? Should replacement therapy be administered routinely or as rescue therapy? Should preventive treatment be started before, during or after withdrawal? What are the most effective preventive treatments? Should patients be managed through inpatient or outpatient withdrawal programmes? What is the best approach to adopt in preventing relapses? Treatment of $\mathrm{MOH}$ is a difficult challenge, but may be very rewarding. Although there is still a lack of high-quality studies providing evidence-based answers to the many specific questions it raises, neurologists need to know that the combination of education with a rational use of selected therapeutic strategies may be beneficial to people with chronic headache and help to relieve their suffering.

Keywords Medication overuse headache - Therapy · Management $\cdot \mathrm{MOH} \cdot$ Review

\section{Background}

Over the past 15 years, clinical experience and scientific studies on medication overuse headache $(\mathrm{MOH})$ have accumulated, providing the basis for revisions of the International Classification of Headache Disorders (ICHD-II) diagnostic criteria $[1,2]$ and for the proposal (the practical details of which remain to be worked out) of a pragmatic clinical distinction between simple and complicated $\mathrm{MOH}$ (Table 1) [3, 4]. The "New appendix criteria for a broader concept of chronic migraine" recently published by the International Headache Society (IHS) [2] no longer require 
Table 1 Proposed criteria for simple or complex medication overuse headache (see references [3, 4])

\begin{tabular}{|c|c|}
\hline Simple $\mathrm{MOH}$ & Complex $\mathrm{MOH}$ \\
\hline Short duration of $\mathrm{MOH}$ ( 3 months -1 year) & Long duration of $\mathrm{MOH}$ (>1 year) \\
\hline Relatively modest doses of drugs $\mathrm{s}^{\mathrm{a}}$ & $\begin{array}{l}\text { Daily opioids or combination medication with more than } \\
\text { one prescription drug }\end{array}$ \\
\hline $\begin{array}{l}\text { Minimal psychiatric contribution }{ }^{\mathrm{b}} \\
\text { (one or two axis I clinical syndromes) }\end{array}$ & Multiple psychiatric comorbidities including personality disorders \\
\hline No history of relapse after withdrawal & History of relapse following withdrawal \\
\hline
\end{tabular}

${ }^{a}$ Up to two triptans and three analgesics per day

${ }^{\mathrm{b}}$ Psychological issues contributing to the perpetuation of MOH include: (a) the belief that drug(s) is(are) the only solution, (b) anticipatory fear of pain (cephalalgiophobia), (c) difficulty tolerating discomfort, (d) sedation seeking, (e) outside pressure, need to function, (f) axis I, clinical syndrome, (g) axis II personality disorders

headache resolution or a return to the previous headache pattern after drug discontinuation, to confirm the diagnosis. These simplified diagnostic criteria will help physicians to recognise $\mathrm{MOH}$, thus removing the diagnostic barriers to proper care of affected patients. In this scenario, there is an increasing need for evidence-based and cost-effective drug withdrawal strategies.

Drug withdrawal is the treatment of choice for $\mathrm{MOH}$ [5-7]. Zeeberg et al. recently reported that mere discontinuation of regular drug intake had, after 2 months, reduced the mean headache frequency by $51 \%$ in migraine, $18 \%$ in tension-type headache (TTH) and $33 \%$ in patients with a combination of migraine and TTH [8]. They also found that $\mathrm{MOH}$ patients who had previously failed to respond to preventive treatment became responsive to medical prophylaxis after withdrawal of the acute headache drugs they had been overusing [9]. A survey of 22 studies dealing with the therapy of drug-induced headache revealed that most centres used drug withdrawal as the first-choice therapy [5]. Drug withdrawal, however, is performed very differently within and across countries and therapeutic recommendations for the acute phase of detoxification thus vary considerably among studies. Moreover, the IHS only recently published its guidelines for controlled trials of prophylactic treatment in chronic migraine, including $\mathrm{MOH}$ [10]. Currently, there is a lack of prospective, controlled trials in this field, and treatment effectiveness is basically inferred from the results of openlabel trials, retrospective case reviews, anecdotal observations, clinical experience and generalisations from the literature on primary headaches. As a result, no formal evidence-based recommendations for optimal therapy can be made and, in general, published guidelines reflect the personal experience of the authors and/or the best available evidence [11-14].

Basically, the aims of $\mathrm{MOH}$ management are: (a) to withdraw the overused drug; (b) to alleviate withdrawal symptoms by means of a bridge therapy, including pharmacological and non-pharmacological support, designed to help the patient to tolerate the withdrawal process; and (c) to prevent relapse $[13,15]$.

Today, there is extensive debate on the best strategies for achieving these goals and the different aspects of this debate are discussed in this review (Table 2).

\section{Should medication withdrawal be abrupt or gradual?}

No study has compared abrupt withdrawal with tapered withdrawal in prospective randomised trials; therefore, no formal evidence-based recommendation can be made. However, the majority of headache specialists consider drug withdrawal to be more effective if done abruptly $[12-14,16]$. Abrupt withdrawal is possibly associated with less protracted suffering for the patient and faster resolution of the drug-centred pain-coping behaviour.

This is likely to apply particularly in overuse of triptans, ergots, paracetamol, aspirin and NSAIDs, for which outpatient withdrawal programmes can be appropriate. Conversely, due to the possibility of severe withdrawal symptoms, patients overusing opioids, barbiturates or benzodiazepines should have their medication withdrawn gradually (i.e. reduced by $10-20 \%$ every week or two, depending on the overused drug, the dose and the duration of intake), preferably in the context of an inpatient programme (clinical experience-based recommendation).

\section{Should patients receive replacement therapy?}

\section{What are the most effective therapeutic programmes for controlling withdrawal symptoms?}

\section{Should replacement therapy be administered routinely or only as rescue therapy?}

Symptomatic drug withdrawal leads to worsening of headache and the onset of drug withdrawal symptoms such as 
Table 2 Clinical management of $\mathrm{MOH}$ : questions and answers

Should medication withdrawal be abrupt or gradual?

Should patients receive replacement therapy?

What are the most effective therapeutic programmes for controlling withdrawal symptoms?

Should replacement therapy be administered routinely or as rescue therapy?

Should preventive treatment be started before, during or after withdrawal?

What are the most effective preventive treatments?

Should patients be managed through inpatient or outpatient withdrawal programmes?

What is the best approach to adopt to prevent the relapse?
No formal evidence-based recommendation can be made.

The majority of headache specialists consider drug withdrawal more effective if done immediately. In general, triptans, ergots, paracetamol, aspirin and NSAIDs should be stopped abruptly.

Evidence from available controlled trials suggest that non-complicated MOH patients may achieve successful drug withdrawal through the simple imparting of advice to withdraw symptomatic medications and the use of rescue medications with limits on intake.

Patients overusing drugs containing opioids, barbiturates or tranquillisers usually require a replacement therapy (clinical experience-based recommendation).

Although this is not yet supported by scientific evidence, patients overusing analgesics, ergots, combination drugs or combinations of acute medications (especially those using multiple daily doses), who experience intolerable withdrawal symptoms or present medical and psychiatric illnesses that could complicate their withdrawal programme, should be considered for regular replacement therapy, whether symptoms are present or not (clinical experience-based recommendation).

No evidence-based recommendation can be made on the most effective replacement therapy in these patients.

No evidence-based recommendation can be made on the use of preventive treatment (who, when and what) for the clinical management of $\mathrm{MOH}$.

In non-complicated MOH patients, the decision on whether or not to start a preventive treatment may be postponed until a follow-up visit performed 2-3 months after the start of the withdrawal treatment. Complicated $\mathrm{MOH}$ patients, especially those who already had a high headache frequency before development of medication overuse and who had tried more than one preventive treatment in the past, probably need early prophylaxis (clinical experience-based recommendation).

There are no evidence-based indications supporting the use of specific preventive drugs in $\mathrm{MOH}$ (valproic acid as well as topiramate have been shown to have beneficial effects in the prophylactic treatment of chronic migraine, complicated by excessive analgesic intake in open-label and double-blind trials).

No evidence-based recommendation can be made. In non-complicated $\mathrm{MOH}$ patients, effective drug withdrawal may be obtained in an outpatient setting. $\mathrm{MOH}$ patients overusing opioids, barbiturates or benzodiazepines, or presenting psychological problems or medical illnesses liable to complicate withdrawal programmes undertaken on an outpatient basis, are candidates for hospitalisation, as are those who have previously failed as outpatients or who lack the motivation needed to undertake an outpatient withdrawal programme (clinical experience-based recommendation).

The fact that a large proportion of $\mathrm{MOH}$ patients are at risk of relapse after withdrawal provides an indication of the lack of effective strategies for preventing this outcome.

The most practical strategy in $\mathrm{MOH}$ is to prevent medication overuse through education and early and appropriate headache prophylaxis in patients who present a high headache frequency (author's personal view). nausea, vomiting, arterial hypotension, tachycardia, sleep disturbances, restlessness, anxiety and nervousness [5, 6]. Seizures and hallucinations have only rarely been observed, even in patients overusing butalbital-containing agents. Drug withdrawal symptoms typically last $2-10$ days (average 3.5 days), but can persist for up to 4 weeks [7, 14]. Withdrawal symptoms are usually relieved by further intake of the overused medication, but this could lead to perpetuation of the overuse.

Withdrawal symptoms vary greatly depending on the overused medication. The duration of the withdrawal headache is shorter in patients overusing triptans (4.1 days) than in those overusing ergots (6.7 days) or NSAIDs (9.5 days) [17]. Withdrawal from triptans is generally achieved in a short period of time (approximately $80 \%$ of patients are headache-free 4 days after starting the therapy) and without serious withdrawal symptoms [17, 18].

Many different replacement strategies for treating medication withdrawal symptoms in $\mathrm{MOH}$ have been proposed and found to be effective, almost exclusively in uncontrolled, unblinded studies that employed a variety of outcome measures [12, 19]. The proposed treatments include different drug classes (used alone or in combination), such as antiemetics, analgesics, triptans, sedatives, narcoleptics, central muscle relaxants and corticosteroids (the drugs suggested include intravenous dihydroergotamine, lidocaine, intravenous valproic acid, tramadol, clonidine, phenobarbital and amitriptyline), and other 
preventive medications, oxygen, electrical stimulation and fluid replacement [12, 19, 20].

These treatments have been tested both in inpatient and in outpatient regimens. However, the fact that they are often used in combination with preventive and educational interventions makes it difficult to understand the efficiency of the treatments per se, as well as their reproducibility in other settings. Bridge therapies are regularly prescribed, usually administered for short periods, in other cases administered on demand (rescue treatment) and in some cases with limits on intake.

Because all drugs used for the acute treatment of headache can cause $\mathrm{MOH}$, corticosteroids are an attractive option for the treatment of withdrawal headache. In a large open-label trial investigating patients with chronic daily headache and medication overuse, oral prednisone $(60 \mathrm{mg}$ as a starting dose, then tapering down by $20 \mathrm{mg}$ every second day), as part of an outpatient regimen, effectively reduced withdrawal symptoms, including rebound headache [21]. Conversely, a recent Norwegian placebo-controlled study showed that prednisolone $(60 \mathrm{mg}$ as a starting dose, then tapering down by $20 \mathrm{mg}$ every second day), given as part of an inpatient regimen for 6 days, was ineffective in treating withdrawal headache [22]. This latter study included patients with both TTH and migraine. In a very recent study, intended as a proof-of-concept uncontrolled study, prednisone $100 \mathrm{mg}$, given once a day for the first 5 days of withdrawal as part of an inpatient strategy, was effective in reducing medication withdrawal headache in $20 \mathrm{MOH}$ patients with migraine as a primary headache [23]. Thus, in the only high-quality study available, steroids administered in the acute phase of drug withdrawal seem ineffective. High-quality randomised placebo-controlled trials using higher dosages and taking into account the clinical heterogeneity of $\mathrm{MOH}$ are needed.

Three recent prospective randomised controlled trials (two open-label and one double-blind) compared the efficacy of different therapeutic regimens following abrupt withdrawal of the overused medication [22, 24, 25].

Rossi et al. [24] randomly allocated 120 simple $\mathrm{MOH}$ patients (no previous detoxification treatments, no coexistent, significant and complicating medical illnesses, no current psychiatric comorbidity, no overuse of agents containing opioids, benzodiazepines or barbiturates, migraine as primary headache) to one of three groups, each of 40 subjects: Group A received only strong advice to withdraw overused medication(s); Group B underwent a standard outpatient detoxification programme based on advice to withdraw, abruptly, overused medication(s) + oral prednisone for the first 8 days + personalised preventive treatment starting on day 1; Group $\mathrm{C}$ underwent a standard inpatient drug withdrawal programme based on the abrupt discontinuation of overused medication(s) + oral prednisone for the first 8 days + personalised preventive treatment starting on day $1+$ parenteral fluid replacement and administration of antiemetics + close observation and support for 8 days.

Krymchantowski and Moreira [25] randomised 150 MOH outpatients (diagnosed according to the SilbersteinLipton criteria), who were moderate overusers of acute drugs (excluding opioids, barbiturates and tranquillisers), to a tapering course of prednisolone, regular naratriptan or no regular medication for 6 days, in addition to advice and rescue medication (indomethacin or chlorpromazine). All the patients were started on prophylaxis on day 7 (atenolol, nortriptyline or flunarizine).

Boe et al. [22] evaluated $100 \mathrm{MOH}$ inpatients, who had no psychiatric or physical comorbidity and were not overusing opioids or barbiturates; these patients received prednisolone or placebo and pre-withdrawal advice, and were allowed to take antiemetics, antihistaminic drugs and antipsychotics, if necessary.

After a follow-up period ranging from 8 days to 2 months, none of these three studies found any betweengroup differences in:

- the percentage of patients achieving successful withdrawal [24, 25];

- headache frequency [24, 25];

- headache intensity [25];

- calculated mean headache [22].

It is worth noting, however, that in the study by Krymchantowski and Moreira [25], the patients not receiving bridge therapy experienced more symptoms and required more rescue medication.

The findings of available randomised controlled trials indicate that in patients with simple $\mathrm{MOH}$, especially in those with migraine as the primary headache, effective drug withdrawal can be achieved through the imparting of advice alone, although the use of medication (on a routine or rescue basis) can be effective as well. This may have important economic implications, if we consider the costs, per detoxified patient, of the different strategies emerging in the study by Rossi et al.: the simple imparting of advice, $€ 40$; the outpatient programme (including replacement therapy), €116; and the inpatient programme, €2,876 (Rossi et al., unpublished data).

In summary:

(a) Simple $\mathrm{MOH}$ patients may achieve successful drug withdrawal through the simple imparting of advice to withdraw symptomatic medications and the use of rescue medications with limits on intake (evidence from available randomised controlled trials). Effective education of $\mathrm{MOH}$ sufferers is crucial to proper management, and information should be imparted to 
all patients in accordance with the principles summarised in Table 3. Rescue treatment should be tailored to the patient on the basis of his or her medical history, headache characteristics and previous therapeutic experiences, and adherence to the rule that patients should not be prescribed, as a rescue drug, the drug that they had been overusing.

(b) Patients overusing drugs containing opioids, barbiturates or tranquillisers require a replacement therapy regimen, which may include the short-term use of long-acting opioids, phenobarbital, clonidine (depending on the overused drug), hydration and, if necessary, antiemetics [12-14, 20]. No formal recommendation on support therapy in these patients can be made and placebo-controlled studies are needed.

(c) Although this is not yet supported by scientific evidence, patients overusing analgesics, ergots, combination drugs or combinations of acute medications (especially those using multiple daily doses), who experience intolerable withdrawal symptoms or present medical and psychiatric illnesses that could complicate their withdrawal programme, should be considered for regular replacement therapy, whether symptoms are present or not. No formal recommendation can be made on the most effective replacement therapy in these patients. A single course of naproxen or tapered steroids, with or without antiemetics, and adequate hydration are the therapeutic measures most frequently included in guidelines suggested by experts [12-15, 19, 20]. Again, well-designed, double-blind controlled trials are needed.

\section{Should preventive treatment be started before, during or after withdrawal?}

High-quality studies investigating the usefulness of preventive treatment in the acute phase of drug withdrawal are lacking. In the study by Rossi et al. [24], personalised preventive therapy started on day 1 did not improve the outcome of withdrawal therapy. In the Danish study of 175 MOH patients [8], preventive therapy was initiated after a 2-month withdrawal period and actually found to be necessary in only $47 \%$ of the patients; in the other $53 \%$, headache frequency was markedly reduced simply by discontinuation of the overused medication (in this study, 36\% of the patients failed to remain drug-free after receiving advice to withdraw the overused medication). Hagen et al. [26], in a recently published prospective, multicentre study, investigated the effect of early introduction of prophylactic treatment in three groups of $\mathrm{MOH}$ patients. In the prophylaxis group $(n=17)$, patients received personalised preventive medication from day 1 ; the abrupt withdrawal group ( $n=20$ patients) received advice to withdraw abruptly the overused medication plus rescue therapy, whilst the controls $(n=19)$ received no preventive medication and no explicit advice to withdraw the overused medication. The primary outcome measure, i.e. the change in headache days/month, was not found to differ significantly among groups. The prophylaxis group recorded the most consistent reduction in headache days/month at months 3,5 and 12 , though the mean headache frequency continued to be greater than 15 days/month in all the groups. All three groups recorded significant reductions in days with use of acute medication per month, when compared with baseline, the change being greatest in the abrupt withdrawal group versus the controls $(-19.1$ vs. -6.9 at month $3, p=0.002$ ). The prophylaxis group, compared with the withdrawal group, showed significantly more pronounced reductions in total headache index at months 3 and 12, and in sick leave days/month at months 5 and 12 . During the follow-up, the proportion of responders, defined as patients no longer overusing symptomatic medications or with a greater than $50 \%$ reduction in headache days, tended to be higher in the prophylaxis group. The authors concluded that early introduction of preventive treatment, in the absence of previous detoxification reduced total headache suffering more persistently than abrupt withdrawal, challenging the notion that drug withdrawal is necessary to obtain reduced headache frequency and a response to prophylactic treatment. Unfortunately, the results of this study are weakened by several methodological flaws. First, all the patients received written information on $\mathrm{MOH}$ and the therapeutic importance of withdrawing the acute medication, and this may have influenced the behaviour both of the prophylaxis group members and the controls (indeed, 26\% of the controls
Table 3 Pillars of the educational approach to $\mathrm{MOH}$ sufferers

\footnotetext{
Explanation of the role of medication overuse in making headache chronic and in reducing the effectiveness of preventive and behavioural treatments

Explanation in detail of the phenomenon and symptoms of withdrawal headache

Emphasis on the beneficial long-term effects, on headache natural history, of reducing symptomatic medication intake (including reduction of the disease-reinforcing properties of short-term pain relief)

Discouragement of anticipatory use of medication

Emphasis on the need for a detoxification programme prior to other therapeutic options
} 
spontaneously reduced their drug intake considerably). Second, since $72 \%$ of the patients in the withdrawal group received a preventive therapy at month 3 , the differences observed from month 5 to 12 may be only poorly attributable to the different initial therapeutic strategies. Furthermore, in view of the heterogeneity of $\mathrm{MOH}$, the number of patients included in the study, which was below the power calculation, was too low. In addition, almost $30 \%$ of the $\mathrm{MOH}$ patients included in this study overused opioids (vs. $42 \%$ of the controls); opioid overusers are usually excluded by studies of this kind, investigating the effectiveness of different treatment strategies in $\mathrm{MOH}$, because they can present withdrawal symptoms liable to complicate the withdrawal process, and this aspect may have contributed to determining the low success rate observed in this study. Finally, with regard to the differences in the outcome measures observed at month 3, only the reduction in headache index showed a statistical difference among groups in favour of the prophylaxis group; for all the other parameters, only non-significant differences were observed. For all the above reasons, the authors' conclusions appear speculative. There is still a need for further prospective, large-scale randomised trials to establish the usefulness of early preventive treatment for $\mathrm{MOH}$.

In summary:

(a) In simple $\mathrm{MOH}$ patients, the decision on whether or not to start a preventive treatment may be postponed until a follow-up visit performed 2-3 months after the start of the withdrawal treatment (clinical experiencebased recommendation). This approach may help patients to feel more in control of their headache, and it also fits better with what is known about the natural history of the disease.

(b) An alternative approach is to start preventive and withdrawal treatments simultaneously, or to start preventive therapy during the washout period, making it clear to the patient that the treatment may not become fully effective until MOH has been eliminated. This approach has two potential advantages: first, it may help to reduce reliance on symptomatic medications, and, second, the prophylactic treatment may improve the withdrawal symptoms and headache frequency.

Complicated $\mathrm{MOH}$ patients, especially those who already had a high headache frequency before medication overuse developed and who had tried more than one preventive treatment in the past, probably need early prophylaxis. But, currently no formal evidence-based recommendation can be made on the use of preventive treatment (who, when and what) for the clinical management of $\mathrm{MOH}$.
What are the most effective preventive treatments?

In the absence of evidence-based indications, the choice of preventive agent in $\mathrm{MOH}$ patients should be based on the primary headache type (migraine or TTH), the drug sideeffect profile, the presence of any comorbid and coexistent conditions, and the patient's preferences and previous therapeutic experiences [15].

In clinical practice, a monotherapy approach is preferable, selecting from the possible first-line treatments: betablockers, tricyclic antidepressants, calcium antagonists, tizanidine or anticonvulsants. It seems reasonable to start with low dosages, to reduce the risk of adverse events, and then to increase the dose progressively until a therapeutic effect or adverse events appear [12-14]. Only when such a first-line monotherapy approach fails does it become advisable to look for an alternative second- or third-line treatment.

In open-label trials, both valproic acid and topiramate have shown beneficial effects in the prophylactic treatment of chronic daily headache complicated by excess analgesic intake $[27,28]$. More recently, a double-blind trial tested the efficacy and safety of topiramate in patients with a diagnosis of chronic migraine and $\mathrm{MOH}$ [29]. A total of 32 patients in the intent-to-treat population received topiramate and 27 patients received placebo for a period of 16 weeks ( $78 \%$ of these subjects met criteria for $\mathrm{MOH}$ ). Topiramate was titrated ( $25 \mathrm{mg}$ weekly) to a target dose of $100 \mathrm{mg} /$ day, allowing dosing flexibility from 50 to $200 \mathrm{mg} /$ day, according to patient need. Topiramate produced a significant reduction in the mean number of migraine days/month compared with placebo $(-3.5 \pm 6.3$ vs. $-0.2 \pm 4.7, p<0.05$ ). There emerged no significant between-group differences in health-related quality of life. The MIDAS questionnaires showed improvements in the topiramate treatment group $(p=0.042$ vs. placebo). Treatment-emergent adverse events were reported by $75 \%$ of the topiramate-treated patients (vs. $37 \%$ in the placebo group). This randomised, double-blind, placebo-controlled trial demonstrated that topiramate is effective, although associated with a higher incidence of side effects when used for the preventive treatment of chronic migraine, even in the presence of $\mathrm{MOH}$. However, the reported improvement in terms of headache frequency appears poor and not sufficient to constitute a reversion of the headache to its previous episodic form.

There is thus a need for further well-designed, doubleblind, controlled trials investigating the effectiveness of other preventive treatments, and prolonged, longer followup periods.

Single injections of the greater occipital nerve with anaesthetics or corticosteroids have been reported as helpful in providing temporary relief from headache even 
Table 4 Published recommendations for outpatient and inpatient withdrawal from headache medication

\begin{tabular}{|c|c|c|}
\hline & Inpatient & Outpatient \\
\hline Pamelaire et al. [12] & $\begin{array}{l}\text { Drugs (opioids/barbiturates) } \\
\text { Status migrainosus } \\
\text { Severe vomiting/dehydration } \\
\text { Social situation } \\
\text { Previous failure as outpatient } \\
\text { Psychiatric comorbidity } \\
\text { Physical comorbidity } \\
\text { Fear of drug interactions }\end{array}$ & $\begin{array}{l}\text { Motivated patients } \\
\text { Mild-moderate overuse }\end{array}$ \\
\hline $\begin{array}{l}\text { German Migraine and Headache } \\
\text { Society (1999) }\end{array}$ & $\begin{array}{l}\text { Drugs (codeine, barbiturates, tranquillisers) } \\
\text { Depression }\end{array}$ & $\begin{array}{l}\text { Drugs (monosubstances, analgesic mixture not } \\
\text { containing barbiturates or codeine) }\end{array}$ \\
\hline Obermann and Katzarava [14] & Previous medication withdrawal failure & $\begin{array}{l}\text { Highly motivated patients } \\
\text { Possibility of daily follow-up visits } \\
\text { Overall good compliance }\end{array}$ \\
\hline $\begin{array}{l}\text { British Association for the Study } \\
\text { of Headache (2007) }\end{array}$ & $\begin{array}{l}\text { Drugs (overuse of high doses of opioids/ } \\
\text { barbiturates/benzodiazepines) } \\
\text { Presence of psychiatric/behavioural disturbances } \\
\text { (in these cases the authors recommend referral to } \\
\text { specialist units or pain management clinics } \\
\text { offering neurological and psychiatric services) }\end{array}$ & $\begin{array}{l}\text { No specific indication (the authors state that } \\
\text { admission to a hospital is rarely } \\
\text { necessary) }\end{array}$ \\
\hline
\end{tabular}

in $\mathrm{MOH}$ patients, but further controlled studies are needed to confirm these findings [30].

\section{Should patients be managed in inpatient or outpatient withdrawal programmes?}

Rossi et al. [24], in their study of 120 patients with migraine plus $\mathrm{MOH}$, low medical needs and no previous detoxification therapy, found simple advice to be as effective as structured inpatient and outpatient detoxification programmes in achieving withdrawal from the overused medication (approximately $75 \%$ of patients in all groups). In addition, the level of adherence to treatment was comparable with all three strategies (almost $90 \%$ of the initial sample completed the study). These results are in line with those of a previous German study, which suggested that outpatient and inpatient programmes could be equally effective [31]. Sick leave of 1 or 2 weeks may be needed when patients are detoxified in an outpatient setting.

The inpatient therapeutic setting offers at least three indisputable advantages. Namely, it allows: (1) close monitoring of the patient's medication intake and clinical conditions, (2) prompt and adequate treatment of withdrawal headache and associated symptoms; (3) the administration of drugs that need continuous medical monitoring (e.g. lidocaine, intravenous ergot derivatives). As discussed in the previous paragraphs, different supportive medication regimens have been proposed.
Headache experts and academic societies have published recommendations that offer criteria for deciding between in- and outpatient approaches (Table 4). It is generally agreed that $\mathrm{MOH}$ patients overusing opioids, barbiturates or benzodiazepines, or presenting psychological problems or medical comorbidities, liable to complicate withdrawal programmes undertaken on an outpatient basis, are candidates for hospitalisation, as are those who have previously failed as outpatients or who lack the motivation needed to undertake an outpatient withdrawal programme.

These recommendations are not evidence based and reflect, essentially, the authors' experience and beliefs, as well as basic principles of good clinical practice. Furthermore, the indications are not sufficiently specific. For example, psychiatric comorbidity and socio-environmental problems need better categorical and dimensional definition. Finally, these recommendations are the result of experience accumulated in headache clinics. Thus, the reproducibility in other settings (e.g. primary care) of the protocols they suggest remains uncertain. Data from literature indicate that the strategy chosen (outpatient vs. inpatient) is not a significant predictor of the long-term success of withdrawal therapy [31,32].

In summary, effective drug withdrawal may be obtained simply in an outpatient setting, at least in $\mathrm{MOH}$ patients presenting low medical needs and no previous experience of detoxification therapy. Future controlled studies are needed to establish whether outpatient programmes may be considered as the first step in a step-care approach to $\mathrm{MOH}$ 
management, in which patients progress through a sequence of treatments (determined by a combination of perceived effectiveness, safety and cost) until they find an effective one, or as just one of the therapeutic options in a stratified-care approach, in which patients, on the basis of the extent of their medical needs, are assigned to different treatments.

\section{What is the best approach to adopt in preventing relapses?}

As stated by Obermann and Katsarava [14], the long-term management of $\mathrm{MOH}$ is definitely more challenging than acute drug withdrawal. Several studies have investigated the long-term outcome of $\mathrm{MOH}$ following detoxification and carefully evaluated possible relapse predictors.

$\mathrm{MOH}$ following successful drug withdrawal has a variable, but mainly good, prognosis [5]. Success is usually strictly defined as no headache at all or an improvement (in terms of headache days/month) of more than $50 \%$. In a review of 17 studies (1,101 patients), the mean success rate of withdrawal therapy, within a time window of 1-6 months, was found to be $72.4 \%$ [5]. Three further studies considered a longer observation period (9-35 months) [31-33] and recorded success rates of 60,70 and $73 \%$, respectively. Longer-term follow-up studies (4-6 years) found relapse rates of between 40 and $60 \%$ [34-40]. These studies are largely heterogeneous with regard to the definition of $\mathrm{MOH}$, populations under study, types of medication overused, types of original primary headache, therapeutic approaches and many other variables. Furthermore, most of them were designed retrospectively.

Recent prospective studies that included patients with triptan-induced $\mathrm{MOH}$ reported relapse rates after successful drug detoxification therapy of $38 \%$ in the first year and around $42 \%$ at 4 years $[38,41]$. Patients with TTH had higher relapse rates than migraine patients (77 vs. $23 \%$, respectively), and analgesic overusers had higher relapse rates than ergot and triptan overusers (58 vs. 18 and 22\%) [41]. In a recent study, from Serbia, of patients not overusing triptans, $39.6 \%$ of 240 patients had relapsed at the 1-year follow-up [32]. The frequency of the primary headache disorder, ergotamine overuse and pre-treatment disability as measured by MIDAS were all found to be predictors of relapse (the reported OR values and CIs actually raise some question marks over the statistical interpretation of the results). These, and older studies investigating rates and predictors of relapse in $\mathrm{MOH}$, were conducted on nonselected populations of headache patients [5, 31, 40]. In a recent publication, Rossi et al. [42] evaluated the rates and predictors of relapse after successful drug withdrawal in a previously studied population of simple $\mathrm{MOH}$ patients with migraine as primary headache. The patients were followed up prospectively for 1 year: relapsers were defined as patients fulfilling, at follow-up, the new ICHD-II appendix criteria for $\mathrm{MOH}$. At the 1-year follow-up, the relapse rate was found to be $20.5 \%$, which is consistent with that reported in the subgroup of patients with $\mathrm{MOH}$ plus migraine studied by Katsarava et al. [41]. A binary logistic regression analysis was performed and three variables emerged as significant predictors of relapse: years with more than eight migraine days per month $(\mathrm{OR}=1.57, p=0.01)$, higher frequency of migraine attacks after drug withdrawal $(\mathrm{OR}=1.48, p=0.04)$, and a greater number of previous preventive treatments $(\mathrm{OR}=1.54, p=0.01)$. This study suggests that in patients with migraine plus $\mathrm{MOH}$ and low medical needs, the occurrence of relapse seems to depend on a greater severity of baseline migraine. In the study by Hagen et al. [26], the reduction in monthly headache days was more pronounced in the individuals who had tried only one or no preventive medications before inclusion than in those who had tried two or more (6.1 vs. 1.3 days, $p=0.02$ ).

In short, the main findings of the investigations addressing the long-term prognosis of $\mathrm{MOH}$ may be summarised as follows:

- the literature data are heterogeneous due to the use of different patient populations;

- relapse after withdrawal therapy is an important concern even in patients with simple $\mathrm{MOH}$;

- TTH patients are more likely to relapse than those with migraine, probably due to the lack of effective TTH prophylactics;

- the majority of patients who relapse do so in the first year after withdrawal (many patients relapse within the first 6 months);

- the withdrawal therapy strategy [31, 33], the use of preventive treatment, the duration of migraine and the duration of drug overuse, as well as socio-demographic variables, have no impact on the outcome [31, 32, 39, 41], whereas discrepancies have emerged with regard to the influence, on $\mathrm{MOH}$ prognosis, of the type of drug overused;

- the role of additional factors, such as psychological and social ones, on $\mathrm{MOH}$ prognosis has not been adequately investigated;

- in MOH that has evolved from migraine as the primary headache, relapse seems to depend on a greater severity of migraine at baseline.

The fact that a large proportion of $\mathrm{MOH}$ patients are at risk of relapse after withdrawal provides an indication of the lack of effective strategies for preventing this outcome. Even though many authors are in favour of starting firstline preventive treatments as soon as possible [13, 14], 
these treatments have no influence on the prognosis. It is generally agreed that behavioural and psychological factors could potentially influence the induction, maintenance and outcome of $\mathrm{MOH}[3,4,6,7,43]$. Consequently, many authors consider the following to be essential aspects of long-term management of $\mathrm{MOH}$ (clinical experience-based recommendation):

- patient education (e.g. suggestions on how to improve self-management of attacks, information on maximal monthly dosages of symptomatic drugs, on what to expect from preventive treatments, etc.);

- continuous support in the first year after withdrawal (frequent follow-up visits, also involving, if necessary, patients'family);

- continuous monitoring by means of a headache diary, and behavioural therapies aiming to correct aberrant pain-coping strategies and psychological factors contributing to $\mathrm{MOH}[4,13-15,44,45]$.

Currently, data on the effectiveness of these measures are limited. In a quasi-randomised controlled trial $(n=61)$ the addition of biofeedback-assisted relaxation therapy to preventive medication did not increase the success rate at 3 years and, though the patients in the combined group were less likely to relapse, this finding did not reach statistical significance when subjected to an intention-to-treat analysis [46]. Recently, in a very limited number of $\mathrm{MOH}$ patients $(n=27)$ having migraine as primary headache, it was shown at the 12-month follow-up that the decrease in headache frequency and medication intake was greater, and the relapse rate lower, in patients receiving psychoanalysis-based psychotherapy in addition to prophylactic treatment than in those receiving only pharmacotherapy [47]. Of course, these findings need to be confirmed in further randomised controlled studies enrolling a larger number of patients.

All these data highlight the urgent need for future research into effective relapse prevention strategies and strengthen the notion that the most practical strategy in $\mathrm{MOH}$ is to prevent medication overuse through education and early, appropriate headache prophylaxis in patients with high headache frequency.

\section{Conclusions}

Management of medication overuse can be very rewarding, but it is, in general, difficult. This is due to a number of inter-related factors. The first, as illustrated, is the lack of high-quality studies providing evidence-based answers to the various specific questions pertaining to the treatment of $\mathrm{MOH}$, which is essentially based on drug withdrawal. $\mathrm{MOH}$ is not simply a highly frequent migraine or TTH and, consequently, efforts to treat $\mathrm{MOH}$ by applying the basic principles of primary headache therapy are often unsuccessful. Second, the pathophysiological mechanisms underlying $\mathrm{MOH}$ are poorly understood. Indeed, $\mathrm{MOH}$ is an extremely heterogeneous disorder with regard to many factors, such as type of primary headache, genetic predisposition, pattern and severity, types of drug overused, psychiatric and physical comorbidities, socio-environmental pressures on individual patients and individual patients' past therapeutic experiences. As a result, there probably exists no single therapeutic strategy that is effective in every patient. Future studies should consider the heterogeneity of $\mathrm{MOH}$, to promote the development of therapeutic strategies that can be tailored to the clinical peculiarities of every single patient. Finally, $\mathrm{MOH}$ is underestimated and, in some way, encouraged by those physicians who instruct patients with a high frequency of attacks to take the symptomatic drug as early as possible, thereby reinforcing a drug-centred pain-coping strategy that is very difficult to reverse.

Currently, the only reasonable strategy is to prevent the development of $\mathrm{MOH}$ by educating patients and providing them with adequate and accurate general information, drawing their attention to the information given in the instructions leaflets contained in the packages of all potential risk drugs and monitoring them closely. More specifically, targeted education and information programmes could effectively increase awareness of this largely underestimated clinical entity. Patients seeking treatment should be informed of the risks of overusing symptomatic headache drugs, the consumption of which should be restricted to a maximum prescribed monthly dosage. As a general rule, a preventive medication should be started when a patient regularly requires acute treatment on more than 2 days a week. Early initiation of headache prophylaxis, either a medical or a behavioural approach, is a powerful means of avoiding $\mathrm{MOH}$. Headache drugs containing barbiturates, caffeine, codeine or sedatives, as well as mixed analgesics, are the worst offenders and should be avoided. The main problem is that these compounds are available as over-the-counter drugs and those who use them may not seek professional and more adequate treatment. International and national institutions should step up their efforts to spread the message that frequent use of acute attack medication constitutes misuse. Future longitudinal population-based studies will help us to identify the patients who are at risk of developing $\mathrm{MOH}$ and to adjust preventive strategies accordingly.

Acknowledgments This manuscipt was prepared with funding from and within the activities of the COMOESTAS Project, VII FP, EC contract number 215366 (COMOESTAS) FP7-Thematic priority ICT (http://www.comoestas-project.eu).

Conflict of interest None. 


\section{Appendix}

C. Tassorelli (Project Manager), M. Allena, G. Sances, G. Sandrini, F. Blandini (IRCCS "Neurological Institute C. Mondino" Foundation, University Centre for Headache and Adaptive Disorders, Pavia), L. Bendtsen, S.B. Munksgaard (Danish Headache Centre, Glostrup Hospital), M. Lainez, B. Lopez (Fundación de la Comunidad Valenciana para la Investigación Biomédica, la Docencia y la Cooperación Internacional y para el Desarrollo del Hospital Clínico Universitario de Valencia, Spain), Z. Katsarava, D. Mueller (Department of Neurology, University Hospital of Essen), J. Leston, M.T. Goicoichea (Fundacion para la Lucha contra las Enfermedades Neurologicas de la Infanzia, Buenos Aires, Argentina), R. Fadic, B. Shand (Pontificia Universidad Catolica de Chile, Santiago, Chile).

\section{References}

1. Silberstein SD, Olesen J, Bousser MG, Diener HC, Dodick D, First $\mathrm{M}$ et al (2005) The international classification of headache disorders, 2nd edn (ICHD-II)-revision of criteria for 8.2 Medication overuse headache. Cephalalgia 25:460-465

2. Headache Classification Committee (2006) New appendix criteria open for a broader concept of chronic migraine. Cephalalgia 26:742-746

3. Saper JR, Hamel RL, Lake AE III (2005) Medication overuse headache $(\mathrm{MOH})$ is a biobehavioural disorder. Cephalalgia 25:545-546

4. Lake AE III (2006) Medication overuse headache: biobehavioural issues and solutions. Headache 46(Suppl 3):S88-S97

5. Diener HC, Silberstein SD (2006) Medication overuse headache. In: Olesen J, Goadsby PJ, Ramadan NR et al (eds) The headaches, 3rd edn. Lippincott Williams and Wilkins, Philadelphia, pp 976-977

6. Diener HC, Limmroth V (2004) Medication-overuse headache: a worldwide problem. Lancet Neurol 3:475-483

7. Katsarava Z, Jensen R (2007) Medication overuse headache: where are we now ? Curr Opin Neurol 20:326-330

8. Zeeberg P, Olesen J, Jensen R (2006) Discontinuation of medication overuse in headache patients: recovery of therapeutic responsiveness. Cephalalgia 26:1192-1198

9. Zeeberg P, Olesen J, Jensen R (2006) Probable medicationoveruse headache: the effect of a 2-month drug-free period. Neurology 66:1894-1898

10. Silberstein S, Tfelt-Hansen P, Dodick DW, Limmroth V, Lipton RB, Pascua J, Wang SJ (2008) Guidelines for controlled trials of prophylactic treatment of chronic migraine in adults. Cephalalgia 28:484-495

11. Haag G, Baahr H, Grotemeyer KH, Pfaffenrath V, Ribbat MJ, Diener HC (1999) Prophylaxie und therapie medikamenteninduzierten dauerkopfsschmerzes. Schmerz 13:52-57

12. Pamelaire K, Crevits L, Goadsby PJ, Haube H (2006) Practical management of medication overuse headache. Acta Neurol Belg 106:43-51

13. Steiner TJ, MacGregor EA, Davies PTG for the British Association for the study of Headache (2007) Guidelines for all healthcare professionals in the diagnosis and management of migraine, tension-type, cluster and medication-overuse headache, 3rd edn. http://216.25.100.131/upload/NS.BASH/BASH_ guidelines.2007.pdf. Accessed in April 2008

14. Obermann M, Katsarava Z (2007) Management of medication overuse headache. Expert Rev Neurother 7:1145-1155

15. Nappi G, Rossi P (2004) Management of medication overuse. In: Nappi G, Rossi P (eds) Migraine: current concepts. Current Medical Literature, London, pp 89-91

16. Hering R, Steiner TJ (1991) Abrupt outpatient withdrawal of medication in analgesic abusers migraineurs. Lancet 337:11421443

17. Katsarava Z, Fritsche G, Muessig M, Diener HC, Limmroth V (2001) Clinical features of withdrawal headache following overuse of triptans and other headache drugs. Neurology 57:1694-1698

18. Relja G, Granato A, Bratina A, Antonello RM, Zorzon M (2006) Outcome of medication overuse headache after abrupt in-patient withdrawal. Cephalalgia 26:589-595

19. Smith TR, Stoneman J (2004) Medication overuse headache from antimigraine therapy: clinical features, pathogenesis and management. Drugs 64:2503-2514

20. UK Medicines Information (UKMi) pharmacists for NHS healthcare professionals. Medicine Q\&As. Medication-overuse headache: what is and how to treat it? From the National Electronic Library of Medicine. http://www.nelm.nhs.uk. Accessed in March 2008

21. Krymchantowski AV, Barbosa JS (2000) Prednisone as initial treatment of analgesic-induced daily headache. Cephalalgia 20:107-113

22. Bøe MG, Mygland A, Salvesen R (2007) Prednisolone does not reduce withdrawal headache. Neurology 69:26-31

23. Pageler L, Katsarava Z, Diener HC, Limmroth V (2008) Prednisone vs. placebo in withdrawal therapy following medication overuse headache. Cephalalgia 28:152-156

24. Rossi P, Di Lorenzo C, Faroni J, Cesarino F, Nappi G (2006) Advice alone vs structured detoxification programmes for medication overuse headache: a prospective, randomized, open-label trial in transformed migraine patients with low medical needs. Cephalalgia 26:1097-1110

25. Krymchantowski AV, Moreira PF (2003) Outpatient detoxification in chronic migraine: comparison of strategies. Cephalalgia 23:982-993

26. Hagen K, Albretsen C, Vilming ST, Salvesen R, Grǿnning M, Helde G, Gravdahl G, Zwart JA, Stovner LJ (2009) Management of medication overuse headache: 1 year randomized multicentre open-label trial. Cephalalgia 29:221-232

27. Mathew NT (1991) Valproate in the treatment of persistent chronic daily headache. An open-label study. Headache 31:71-74

28. Mei D, Ferraro D, Zelano G, Capuano A, Vollono C, Gabriele C, Di Trapani G (2006) Topiramate and triptans revert chronic migraine with medication overuse to episodic migraine. Clin Neuropharmacol 29:269-275

29. Diener HC, Bussone G, Van Oene JC, Lahaye M, Schwalen S, Goadsby PJ, TOPMAT-MIG-201(TOP-CHROME) Study Group (2007) Topiramate reduces headache days in chronic migraine: a randomized, double-blind, placebo-controlled study. Cephalalgia 27:814-823

30. Afridi SK, Shields KG, Bhola R, Goadsby PJ (2006) Greater occipital nerve injection in primary headache syndromes-prolonged effect from a single injection. Pain 122:126-129

31. Suhr B, Evers S, Bauer B, Gralow I, Grotemeyer KH, Husstedt IW (1999) Drug-induced headache: long-term results of stationary versus ambulatory withdrawal therapy. Cephalalgia 19:44-49

32. Zidvert-Trajkovic J, Pekmezovic T, Jovanovic Z, Pavlovic A, Mijajlovic M, Radojicic A, Sternic N (2007) Medication overuse headache: clinical features predicting treatment outcome at 1-year follow-up. Cephalalgia 27:1219-1225 
33. Baumgartner C, Wessely F, Bingol C et al (1989) Long-term prognosis of analgesic withdrawal in patients with drug-induced headache. Headache 29:510-514

34. Diener HC, Dichgans I, Scholz E et al (1989) Analgesic-induced chronic headache:long-term results of withdrawal therapy. J Neurol 236:9-14

35. Schnider P, Auli S, Baumgartner C et al (1996) Long-term outcome of patients with headache and drug abuse after inpatient withdrawal: five-year follow-up. Cephalalgia 16:481-485

36. Evers S, Suhr B, Bauer B et al (1999) A retrospective long-term analysis of the epidemiology and features of drug-induced headache. J Neurol 248:802-809

37. Fritsche G, Eberl A, Katsarava Z et al (2001) Drug-induced headache: long-term follow-up of withdrawal therapy and persistence of drug misuse. Eur Neurol 45:229-235

38. Katsarava Z, Mussig M, Dzagniza A, Frietsche G, Diener HC, Limmroth V (2005) Medication overuse headache: rates and predictors for relapse in a 4-year prospective study. Cephalalgia 25:12-15

39. Pini LA, Cicero AF, Sandrini M (2001) Long-term follow-up of patients treated for chronic headache with analgesic overuse. Cephalalgia 21:878-883

40. Tribl GG, Schnider P, Wober C, Aull S, Auterith A, Zeiler K, Wessely P (2001) Are there predictive factors for long-term outcome after withdrawal in drug-induced chronic daily headaches? Cephalalgia 21:691-696
41. Katsarava Z, Limmroth V, Finke M, Diener HC, Fritsche G (2003) Rates and predictors for relapse in medication overuse headache: a 1-year prospective study. Neurology 60:1682-1683

42. Rossi P, Faroni JV, Nappi G (2008) Medication overuse headache: predictors and rates of relapse in migraine patients with low medical needs. A one-year prospective study. Cephalalgia 28:1196-1200

43. Radat F, Creac'h C, Guegan-Massardier E, Mick G, Guy N, Fabre $\mathrm{N}$ et al (2008) Behavioral dependence in patients with medication overuse headache. A cross-sectional study in consulting patients using the DSM-IV criteria. Headache 48:1026-1036

44. Boes CJ, Block DF, Dodick DW (2006) Pathophysiology and management of transformed migraine and medication overuse headache. Semin Neurol 26:232-241

45. Sances G, Ghiotto N, Loi M, Guaschino E, Marchioni E, Catarci T, Nappi G (2005) A CARE: pathway in medication-overuse headache: the experience of the headache centre in Pavia. J Headache Pain 6:307-309

46. Grazzi L, Andrasik F, D'Amico D et al (2002) Behavioral and pharmacologic treatment of transformed migraine with analgesic overuse-outcome at 3 years. Headache 42:483-490

47. Altieri M, Di Giambattista R, Di Clemente L, Fagiolo D, Tarolla E, Mercurio A, Vicenzini E, Tarsitani L, Lenzi GL, Biondi M, Di Piero V (2009) Combined pharmacological and short-term psychodynamic psychotherapy for probable medication overuse headache: a pilot study. Cephalalgia 29:293-299 